\title{
BACTERIOLOGICAL RECOVERY AFTER INTRAMUSCULAR OR INTRACISTERNAL SPIRAMYCIN-BASED DRYING-OFF THERAPY
}

\author{
S. JÁNOSI ${ }^{1}$, A. HuszeniczA ${ }^{2}$, T. HorvÁth ${ }^{2}$, F. GÉmes ${ }^{2}$, Margit KulCsÁR $^{3}$ \\ and G. HUSZENICZA ${ }^{3 *}$ \\ ${ }^{1}$ Central Veterinary Institute, Budapest, Hungary; ${ }^{2}$ Private veterinary practitioners; \\ ${ }^{3}$ Department and Clinic for Obstetrics and Reproduction, Faculty of Veterinary Sciences, \\ Szent István University, H-1400 Budapest, P.O. Box 2, Hungary
}

(Received April 13, 2000; accepted October 30, 2000)

Systemic (intramuscular, IM) vs. local (intracisternal, IC) routes of spiramycin-based drying-off therapy were compared for efficacy on 65 Staphylococcus aureus infected udder quarters of 38 dairy cows. Single-dose $(30,000 \mathrm{IU} / \mathrm{kg}) \mathrm{IM}$ treatment (single IM group) resulted in a similarly low bacteriological recovery rate $(14 \%)$ as seen in the untreated controls $(18 \%)$. IM treatment $(30,000 \mathrm{IU} / \mathrm{kg})$ on 4 consecutive days (4 IM group) resulted in significantly higher quarter-based recovery rates than that in the single IM group. The bacteriological recovery rates obtained in the intracisternal and 4 IM groups were quite similar but remained below $50 \%$. Based on these findings as well as on the high cost of the repeated intramuscular treatment regime there is no reason to give extra preference to the systemic application of spiramycin at drying off in the practice.

Key words: Mastitis, Staphylococcus aureus, drying off therapy, spiramycin

Mastitis is defined as an inflammation of the mammary gland resulting from bacterial infection in most of the cases. Intramammary infections (IMI) may be manifested in clinical form with visible and palpable changes in the udder and/or in the macroscopic appearance of the milk. In certain cases, however, they cause subclinical mastitis with no obvious clinical symptoms, when only the elevated somatic cell count (SCC) of the milk or the presence of other inflammatory markers can be used to detect the affected quarter (Sandholm, 1995; Huszenicza and Stollár, 1993; Huszenicza et al., 1997).

The species of pathogen causing the actual case of mastitis determines the chance of spontaneous or medicine-driven clinical recovery and of complete bacteriological cure (Pyörälä, 1995). In certain cases the clinical symptoms may disappear but the quarter remains infected by the pathogen. Thus, clinical recov-

\footnotetext{
* Corresponding author; Department and Clinic for Obstetrics and Reproduction, Faculty of Veterinary Science, Szent István University, H-1400 Budapest, P.O. Box 2, Hungary; E-mail: gyhuszen@univet.hu; Fax: +36 (1) 478-4207
} 
ery is more common than bacteriological cure. The difference between the clinical and bacteriological forms of recovery may be very obvious first of all in Staphylococcus aureus mastitis. In 35-70\% of the cases this pathogen can survive in the affected milk alveoli, and until the subsequent recurrence of clinical symptoms the continuous elevation of SCC and/or the presence of other inflammatory markers in the milk are the only signs indicating the existence of IMI (Craven, 1987; Kégl et al., 1993; Pyörälä et al., 1994, Pyörälä, 1995; Owens et al., 1997; Pyörälä and Pyörälä, 1998). This pathogen can survive also in the dry period, so the use of antibiotics at drying off is a valuable tool in the management of this disease. Intracisternal slow-release preparations containing certain $\beta$-lactam antibiotics are the most common drugs of choice, but also some macrolides such as spiramycin can be used for this purpose. Due to its pharmacokinetic properties, spiramycin can be administered not only locally but also in a systemic way, although only limited data are available in the literature on its real efficacy in drying-off therapy.

Prompted by the demand raised by the practice, the objective of this work was to assess the actual efficacy of certain macrolides for the treatment of clinical mastitis as well as for dry cow therapy. For this purpose a series of wellcontrolled field trials was planned in large-scale dairy herds. The aim of the current preliminary study was to compare the efficacy of systemic (intramuscular) and local (intracisternal) spiramycin-based drying-off treatment in terms of bacteriological recovery in S. aureus IMI and the postpartum changes of SCC.

\section{Materials and methods}

\section{Herds and animals}

This pilot study was conducted in three commercial large-scale dairy herds. Fifty-seven, 19 and 24 cows with subclinical mastitis (SCC $>500,000$ in the last three months of their lactation) were included in the study on farms 1, 2 and 3, respectively, but only those with $S$. aureus IMI were used for the final evaluation. In each herd the cows were housed in free stalls, and were milked twice daily in double herringbone parlours equipped with Alfa Laval milking equipment. Cows were dried off approximately 60 days before the calculated calving dates. During the dry period the cows were housed in separate stalls and about 1 week before the estimated calving date they were moved to the maternity unit where they stayed until postpartum day 5-7. On farms 1 and 2 the postmilking teat dipping and drying-off treatment of cows were used routinely, but farm 3 did not apply these procedures. In accordance with the Hungarian practice, feeding was based on maize silage and alfalfa or grass hay, completed with concentrate depending on the actual milk yield. 


\section{Sampling and laboratory procedures}

From all udder quarters of the cows aseptic milk samples were collected for bacteriological culture during the last milking out, at drying off and again in the first week after calving. The samples were frozen and stored at $-18{ }^{\circ} \mathrm{C}$ until the microbiological examination. From each sample, $0.01 \mathrm{ml}$ was streaked onto the surface of one-fourth plate of Columbia agar (Merck, KgaA, Darmstadt, Germany) containing 5\% sheep blood and $0.01 \%$ esculin. All the plates were incubated at $37{ }^{\circ} \mathrm{C}$ and were evaluated after 14 to $16 \mathrm{~h}$ and again following an additional $24 \mathrm{~h}$. The colonies were tentatively identified according to their morphology, CAMP test and the type of haemolysis produced. The strains initially characterized as staphylococci were tested in tubes for coagulase production to confirm their identification as $S$. aureus. For the purpose of the current report all other major and minor pathogens isolated were disregarded.

The SCC of the milk was also determined (Fossomatic technology) for each quarter just before drying off, on postpartum days 3-4 and then once a week for further 4 weeks postpartum.

\section{Treatments}

The cows were randomly divided into four treatment groups. (1) The animals in the first group served as untreated controls (number of cows: $\mathrm{n}_{\text {cow }}=21$ ) and no antimicrobials were given to them at drying off. Those in the second and third groups received an intramuscular injection of 30,000 IU/kg spiramycin base ( $5 \mathrm{ml} / 100 \mathrm{~kg}$; Suanovil ${ }^{\circledR} 20$, Rhône Mérieux) (2) in a single dose (single IM group; $\mathrm{n}_{\text {cow }}=25$ ) or (3) for 4 consecutive days (4 IM group; $\mathrm{n}_{\text {cow }}=30$ ). (4) An intracisternal preparation containing 1.2 million IU spiramycin and 100,000 IU neomycin bound to a long-acting excipient (Speciorlac ${ }^{\circledR}$, Rhône Mérieux) was administered into each of the udder quarters in the last group (intracisternal group; $\mathrm{n}_{\text {cow }}=24$ ). All treatments were administered immediately after the last milking out at drying off.

\section{Statistical analyses}

Statistical analyses were performed using the program SPSS ${ }^{\circledR}$ (SPSS Version 7.5, 1996, SPSS Inc., Chicago, Illinois, USA). Chi-square tests for nonparametric features, ANOVA and $t$-test for SCC were used and statistical significance was declared at the $5 \%$ level.

\section{Results}

Staphylococcus aureus was isolated in pure culture only from 65 quarters of 38 cows at drying off (the number of $S$. aureus infected cows and udder quarters in the four treatment groups was as follows: control: $\mathrm{n}_{\text {cow }}=9, \mathrm{n}_{\text {quarter }}=11$; single IM 
group: $\mathrm{n}_{\text {cow }}=9, \mathrm{n}_{\text {quarter }}=14 ; 4$ IM group: $\mathrm{n}_{\text {cow }}=12, \mathrm{n}_{\text {quarter }}=25$; intracisternal group; $\mathrm{n}_{\text {cow }}=8, \mathrm{n}_{\text {quarter }}=15$ ). The udders of the other animals either (1) were infected by other Gram-positive pathogens (mainly by Streptococcus dysgalactiae and Str. uberis), (2) the presence of no bacteria could be verified, or (3) several colonies of contaminating bacteria also grew out. Thus, all of these cows had to be excluded from the current evaluation.

The bacteriological recovery rate was $18 \%$ in the untreated controls. Compared to data of the untreated controls and the single IM group a quite clear tendency of improved bacteriological recovery rate could be seen in the intracisternal and 4 IM groups. However, only the quarter-based difference between the $4 \mathrm{IM}$ and single IM groups was significant $(\mathrm{P}<0.05)$. Even the highest bacteriological cure rate of $S$. aureus infected quarters observed in the 4 IM group remained below $50 \%$. The single intramuscular administration of spiramycin seems to be completely ineffective for the elimination of S. aureus IMI (Fig. 1).

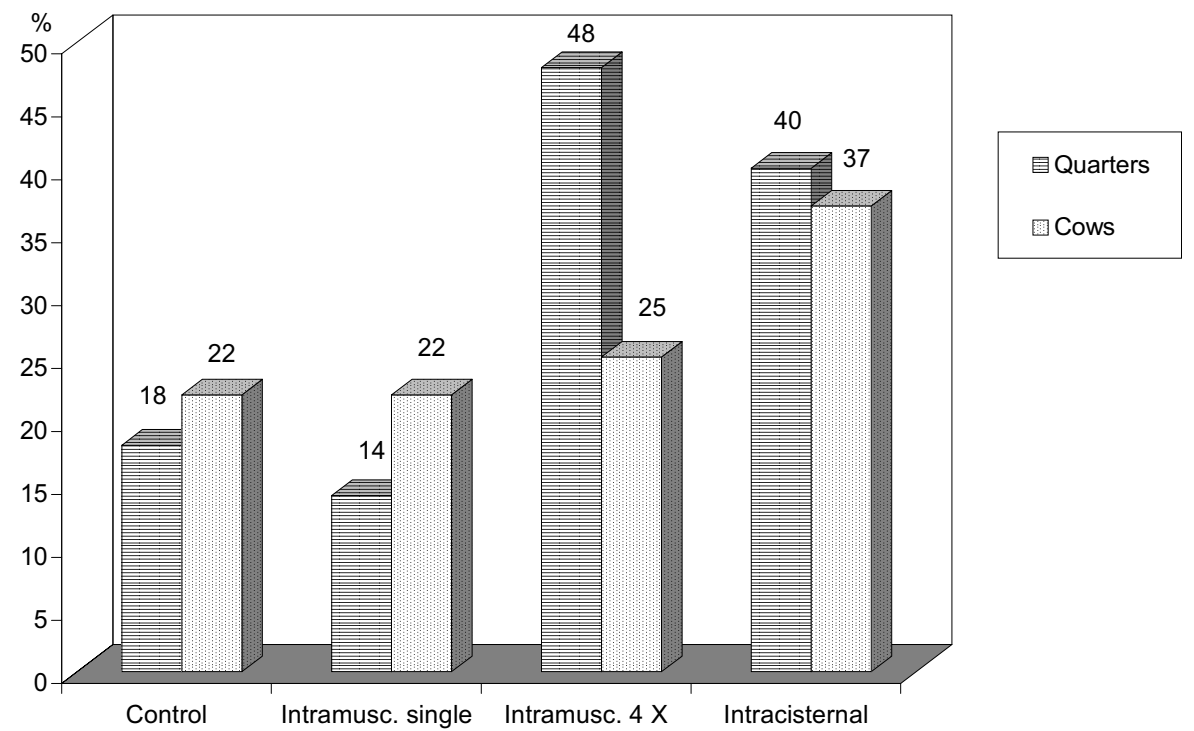

Fig. 1. Bacteriological recovery rates of udder quarters and cows infected with S. aureus at drying off

At drying off the group mean of SCC was about $1 \mathrm{million} / \mathrm{ml}$ in each group and no significant difference was seen among them. In accordance with the bacteriological cure rates observed, the group means of SCC were about $600,000 / \mathrm{ml}$ in the intracisternal and $4 \mathrm{IM}$ groups and about $1,000,000 / \mathrm{ml}$ in the other groups in the 1 st week after calving. These 1 st-week values were followed by a continuous decrease in all groups to the range between $300,000-500,000$ 
(intracisternal and 4 IM groups) or between 500,000 and 800,000 (in other groups). Due to the relatively high rate of overlapping values, however, no significant inter-group differences could be demonstrated.

\section{Discussion}

Both the clinical and subclinical forms of mastitis justify veterinary intervention even if the therapeutic considerations may be different. The acute form of clinical mastitis requires immediate treatment, which aims at rapid elimination of the infective agent and thus may decrease the injuries to the udder tissue. The animal is brought back to production faster and the spread of infection in the herd is prevented (Pyörälä, 1995). Subclinical infections are usually left untreated during lactation, and undergo routine therapy at drying off when there is no milk loss due to treatment and the bacteriological efficacy is higher (Craven, 1987).

Following the local (intracisternal) or systemic (intravenous, intramuscular) administration of antimicrobials the bacteriological recovery rate is affected not only by the in vitro susceptibility of the mastitis pathogen to the injected ingredient but also by several other factors. The pharmacokinetic properties of the antimicrobial, the species of the pathogen, as well as the acute or subacutechronic character, the location and pathological consequences of IMI are regarded as the most important influencing factors (Pyörälä, 1995). In most of the cases the $S$. aureus IMI occurs in chronic form and, as a consequence, very low cure rates are reported (maximum about 50\%; Craven, 1987) when the follow-up bacteriological assessment is made 3 weeks after therapy (Pyörälä and Pyörälä, 1998). Due to the 20-25\% self-recovery rate, the net effect of antibiotics on $S$. aureus is significantly lower than 35-50\% (Sandholm et al., 1991).

Drying-off therapy with antibiotics aims at both the elimination of existing IMI and the prevention of new infections (Neave et al., 1966). During the dry period elimination of the infection with antibiotics is more likely than during lactation as the drug is not milked out but remains in the udder, and a higher and more uniform concentration of ingredients is maintained in the udder (Sandholm and Pyörälä, 1995). The udder is highly susceptible to new infections (mostly caused by environmental pathogens, e.g. Str. uberis) during the first and last weeks of the dry period (Smith et al., 1985; Oliver and Sordillo, 1988), and optimally the therapy should be extended to the whole dry period. During the dry period the udder is naturally resistant to Gram-negative microorganisms, because lactoferrin produced at that time inhibits their establishment. Therefore, antibiotic preparations for dry cows must have good efficacy against $S$. aureus, including strains producing $\beta$-lactamase, as well as against Str. uberis, Str. dysgalactiae, Str. agalactiae and, if the prevention of summer mastitis is desired, they should also be effective against Actinomyces pyogenes (Jonsson, 1993; Ziv, 1994). Intra- 
mammary injectors containing cloxacillin, oxacillin, nafcillin, cephalosporins and spiramycin are therefore widely offered for use.

Spiramycin is an antibiotic substance with a macrolide structure. It is a weak organic base with lipophilic character. In general, macrolides are very suitable drugs for systemic treatment of mastitic cows, as they easily penetrate from blood into milk (Ziv, 1980). Spiramycin has also been shown to accumulate in macrophages in 20 times higher concentrations than in the medium (Desnottes and Diallo, 1990). Both of the above characteristics are very useful when combating inactive, intracellular (intramacrophagic) $S$. aureus in microabscesses. However, spiramycin has only bacteriostatic (and not bactericidal) effect, and due to its long-lasting accumulation in milk the withdrawal time is too long to allow the use of spiramycin in lactating cows (Jonsson, 1993). The pharmacokinetic properties of spiramycin support the idea that it may be a potent antimicrobial to eliminate (contagious) gram-positives including $S$. aureus IMI at drying off (Rhône Merieux, 1991; Jonsson, 1993). Spiramycin has been formulated for both systemic and intracisternal drying-off therapy. The only existing intracisternal preparation used also in this study contains spiramycin in combination with an aminoglycoside (neomycin). Under in vitro conditions neomycin is usually active against $S$. aureus. However, in the mammary gland most of these bacteria are located deep in the udder tissue in damaged milk alveoli surrounded by fibrotic tissue. Some of them may be phagocytosed by neutrophilic granulocytes, but they can survive intracellularly in L form within the lysosomes of these cells. Due to these conditions aminoglycosides, such as neomycin, are unable to reach and kill them (Sandholm et al., 1990; Jonsson, 1993).

Compared with local (intracisternal) administration, the systemic (intramuscular or intravenous) way of dry cow therapy may have some advantages. Besides the avoidance of new infection which is a known possible risk with the administration of intramammary preparations (Boddie and Nickerson, 1986), a higher bacteriological cure rate of IMI can also be expected due to a better distribution of the suitable drug in the udder tissue (Ziv, 1980; Jonsson, 1993). However, only few papers dealing with systemic dry cow therapy have been published. Bolourchi et al. (1996) found that systemic enrofloxacin or tylosin (a macrolide related to spiramycin) at drying off approached but did not exceed the efficacy of local treatment with nafcillin, penicillin and dihydrostreptomycin.

In this experiment single and repeated intramuscular spiramycin treatment at drying off were compared with local (intracisternal) spiramycin + neomycin therapy as well as with untreated controls. Single IM treatment was also chosen as a practical regime. The $4 \mathrm{IM}$ regime was based on the assumption that longer therapy might result in a higher cure rate (Sandholm, 1995). Spiramycin was administered in the normal dose suggested by the manufacturer $(30,000 \mathrm{IU} / \mathrm{kg})$.

The single IM treatment produced similar very low quarter-based bacteriological cure rate $(14 \%)$ as seen in the untreated controls $(18 \%)$. In accordance 
with these bacteriological findings the SCC remained elevated $(>400,000 / \mathrm{ml})$ in the early weeks of the subsequent lactation, indicating the presence of chronic IMI and subclinical mastitis in most of these cases. When administered intramuscularly, spiramycin in a dose of 30,000 IU/kg can produce a 24-hour drug level above the in vitro MIC of $S$. aureus in milk (Ziv, 1976) which seems, however, to be too short for the elimination of this pathogen. Due to its short effect, this treatment must also have failed to prevent new IMI during the dry period. This idea is supported by the observation that the $4 \mathrm{IM}$ treatment regime resulted in a significantly higher quarter-based cure rate (48\%). The about $40 \%$ bacteriological cure rates in the intracisternal and 4 IM groups were almost the same. Our observations verifying the relatively low efficacy of any of these treatments against $S$. aureus IMI show a close agreement with the results of others (Craven, 1987; Bolourchi et al., 1996), and do not support the earlier expectations (Rhône Merieux, 1991; Jonsson, 1993) concerning the outstanding value of this antimicrobial in the management of $S$. aureus mastitis.

If more than one udder quarter of a cow proved infected at drying off $(75 \%$ of the cows in the 4 IM group and 50\% the cows in the IC group), in most of the cases at least one of their quarters remained uncured after calving. Thus the individual-based evaluation of bacteriological cure rates gave even poorer results than the quarter-based evaluation. These findings suggest that antibacterial therapy has questionable value in cows with more than one infected udder quarters.

It can be concluded that the single IM treatment regime is not an effective way of drying-off therapy against $S$. aureus. If intramuscular spiramycin administration was continued for 4 days, or if this ingredient was injected intracisternally in the form of a preparation developed for drying-off therapy, the efficacy was higher but remained below $50 \%$. Due to the high cost of the repeated intramuscular treatment regime there is no reason to give extra preference to this therapy in the practice. Therefore, it was decided not to continue this pilot study.

\section{References}

Boddie, R. L. and Nickerson, S. C. (1986): Dry cow therapy: effects of method of drug administration on the occurrence of intramammary infection. J. Dairy Sci. 69, 253-257.

Bolourchi, M., Hovareshti, P. and Tabatayi, A. H. (1996): Comparison of the effects of local and systemic dry cow therapy for staphylococcal mastitis control. Prev. Vet. Med. 25, 63-67.

Craven, N. (1987): Efficacy and financial value of antibiotic treatment of bovine clinical mastitis during lactation - a review. Br. Vet. J. 143, 410-422.

Desnottes, J. F. and Diallo, N. (1990): Comparative study of intramacrophagic penetration and action on phagocytosis of a macrolide (spiramycin) and a fluoroquinolone (pefloxacin). Pathol. Biol. Paris 38, 281-285.

Huszenicza, Gy. and Stollár, Zs. (1993): Possibilities for diagnosis of subclinical mastitis: a review (in Hungarian, with English abstract). Magyar Állatorvosok Lapja 48, 460-465. 
Huszenicza, Gy., Kégl, T., Kulcsár, M., Oláh, B., Gacs, M., Oppel, K., Stollár, Zs., Jonsson, P. and Jánosi, Sz. (1997): Diagnostic value of certain mastitis markers in following up the clinical and bacteriological changes in pharmacotherapeutic studies. Acta Vet. Hung. 45, 409-416.

Jonsson, P. (1993): Scandinavian system of the bacteriological diagnosis and aimed antimicrobial treatment of mastitis (in Hungarian, with English abstract). Magyar Állatorvosok Lapja 48, $467-471$.

Kégl, T., Huszenicza, Gy., Jonsson, P., Oláh, B., Gacs, M., Stollár, Zs. and Oppel, K. (1993): Experiences on the efficacy of a new intramammary infusion not containing antibiotics: III. Comparative study on the efficacy of a purified propolis-containing udder infusion (in Hungarian, with English abstract). Magyar Állatorvosok Lapja 48, 485-493.

Neave, F. K., Dodd, F. H. and Kingvill, R. G. (1966): A method of controlling udder disease. Vet. Rec. 78, 521-522.

Oliver, S. P. and Sordillo, L. M. (1988): Udder health in the periparturient period. J. Dairy Sci. 71, 2584-2606.

Owens, W. E., Ray, C. H., Watts, J. L. and Yancey, R. J. (1997): Comparison of success of antibiotic therapy during lactation and results of antimicrobial susceptibility tests for bovine mastitis. J. Dairy Sci. 80, 313-317.

Pyörälä, S. (1995): Staphylococcal and streptococcal mastitis. Therapy of clinical mastitis. In: Sandholm, M., Honkanen-Buzalski, T., Kaartinen, L. and Pyörälä, S. (eds) The Bovine Udder and Mastitis. University of Helsinki, Faculty of Veterinary Medicine, pp. 143-148 and 201-208.

Pyörälä, S. and Pyörälä, E. O. (1998): Efficacy of parenteral administration of three antimicrobial agents in treatment of clinical mastitis in lactating cows: 487 cases (1989-1995). J. Am. Vet. Med. Assoc. 212, 407-412.

Pyörälä, S., Pyörälä, E. O. and Trenti, F. (1994): Efficacy of systemic therapy in bovine clinical mastitis during lactation. Proc. $18^{\text {th }}$ World Buiatrics Cong. Bologna, Italy. Vol. 1, pp. 571-574.

Rhône Merieux (1991) (ed.): Control and Treatment of Bovine Mastitis. Spiramycin: the Outstanding Antibiotic. Manufacturer's manual. Paris.

Sandholm, M. and Pyörälä, S. (1995): Dry cow therapy. In: Sandholm, M., Honkanen-Buzalski, T., Kaartinen, L. and Pyörälä, S. (eds) The Bovine Udder and Mastitis. University of Helsinki, Faculty of Veterinary Medicine, pp. 209-214.

Sandholm, M. (1995): Inflammation in mastitis. A critical view on antibacterial mastitis therapy. In: Sandholm, M., Honkanen-Buzalski, T., Kaartinen, L. and Pyörälä, S. (eds) The Bovine Udder and Mastitis. University of Helsinki, Faculty of Veterinary Medicine, pp. 59-75 and 169-186.

Sandholm, M., Ali-Vehmas, T., Nyholm, K., Honkanen-Buzalski, T. and Louhi, M. (1991): Failure mechanisms in lactational therapy of staphylococcal mastitis. Flem. Vet. J. 62, 171-186.

Sandholm, M., Kaartinen, L. and Pyörälä, S. (1990): Bovine mastitis - why does antibiotic therapy not always work? An overview. J. Vet. Pharmacol. Ther. 13, 248-260.

Smith, K. L., Todhunter, D. A. and Schöneberger, P. S. (1985): Environmental pathogens and intramammary infection during the dry period. J. Dairy Sci. 68, 402-417.

Ziv, G. (1976): Experiments with spiramycin/neomycin intramammary dry-period treatment. 9e Congres International sur les Maladies du Betail, Paris. Rapports \& Resumes. Tome 2, pp. $1065-1072$.

Ziv, G. (1980): Drug selection and use in mastitis: systemic vs. local therapy. J. Am. Vet. Med. Assoc. 176, 1109-1115.

Ziv, G. (1994): Good practice in the treatment of mastitis: selecting the ideal. SFB, Paris, pp. 206-218. 